\title{
Penerapan Algoritma Naïve Bayes untuk Rekomendasi Pakaian Wanita
}

\author{
Ratih Yulia Hayuningtyas \\ STMIK Nusa Mandiri/Teknik Informatika \\ Email: ratih.ryl@nusamandiri.ac.id
}

\begin{abstract}
Abstrak
Banyak kegiatan jual beli yang dilakukan secara online yang tentunya sangat memudahkan bagi para pembeli. Salah satunya yaitu pembelian pakaian wanita, dalam memilih sebuah pakaian terkadang sebagai wanita merasa sangat membingungkan, dikarenakan banyak pilihan yang menarik. Selain itu ada beberapa faktor yang menjadi pertimbangan seperti tipe tubuh, bahan, model, warna dan harga. Dari faktor tersebut dibutuhkan sistem untuk rekomendasi pada saat pembelian pakaian wanita terutama yang dilakukan secara online. Algoritma Naïve Bayes merupakan pengklasifikasian probabilistik sederhana yang menghitung sekumpulan probabilitas dengan menjumlahkan frekuensi. Dengan Naîve Bayes diharapkan dapat memberikan keputusan yang akurat dalam menentukan rekomendasi pakaian wanita dengan atribut yang sudah ditentukan seperti style, price, rating, size, season, neckline, sleevelength, waiseline, material, fabrictype, decoration, patterntype, recommendation.
\end{abstract}

\begin{abstract}
Many activities buying and selling are carried out online, which of is very easy to buyer. One of them in the purchases of women's clothing, in choosing a clothing somestime feels very confusing because there are many interesting choice. Apart of there are several factors that considered such as body type, material, model, color and price. From the factors is needed system for recommendations when purchasing women's clothing, especially those online. Naïve Bayes Algorithm is simple probabilitc classification that calculates set of probabilities by summing frequencies. The Naïve Bayes is expected to provide accurate decisions in determining recommendations for women's clothing such as style, price, rating, size, season, neckline, sleevelength, waiseline, material, fabrictype, decoration, patterntype,
\end{abstract} recommendation.

Keywords: Naïve Bayes, Rekomendasi

\section{Pendahuluan}

Sebagian dari wanita terkadang dalam memilih pakaian sangat membingungkan. Seperti pada saat melakukan pembelian pakaian pasti membutuhkan masukan atau pendapat dari orang lain mengenai baju yang akan dipilih, dimulai dari model, harga, bahan, ukuran dan sebagainya yang sesuai. Hal seperti ini sering membuat sebagian orang menjadi kesulitan dan membingungkan untuk memilih sebuah pakaian.

Sudah banyak penjualan yang dilakukan secara online, tentunya sangat memudahkan bagi para pembeli untuk tidak datang lagi ke sebuah toko. Tetapi untuk membeli pakaian secara online harus melihat terlebih dahulu kualitas dan kuantitas dari barang yang dijual. Seperti stok dari barang yang dijual masih tersedia atau tidak dan yang lebih penting lagi yaitu kualitas dari pakaiannya.

Kecocokan seseorang dalam memilih sebuah pakaian dapat dipengaruhi oleh beberapa faktor seperti tipe tubuh yang dimiliki. Tipe tubuh ini banyak macamnya seperti tipe apel, pear, persegi, dan jam pasir (Mariana, Setiawan, \& Irawan, 2015).

Selain itu, harus melihat deskripsi dari pakaian dan ulasan dari pakaian yang akan dibeli seperti bahan dari pakaian, model, warna, harga, corak dan rating dari para pembeli yang sudah membeli pakaian tersebut. Itu semua sangat dibutuhkan sebagai rekomendasi pada saat melakukan pembelian pakaian secara online. Untuk itu dibutuhkan suatu sistem yang dapat membantu dalam menentukan rekomendasi pakaian. 
Sistem pendukung keputusan merupakan sistem informasi interaktif yang menyediakan informasi, pemodelan dan pemanipulasian data. Sistem ini digunakan untuk membantu dalam pengambilan keputusan (Suryadi \& Harahap, 2018)

Pada penelitian ini menggunakan metode Naive Bayes dalam menentukan rekomendasi pakaian wanita. Naive bayes merupakan metode untuk klasifikasi yang menghitung probabilistik dengan dengan menjumlahkan frekuensi dan kombinasi nilai dari dataset yang diberikan untuk menentukan probabilitas hasil (Medkhar, Bote, \& Deshmukh, 2013)

Selain itu, menurut (Saleh, 2015) Naive Bayes merupakan sebuah pengklasifikasian probabilistik sederhana yang menghitung sekumpulan probabilitas dengan menjumlahkan frekuensi dan kombinasi nilai dari dataset yang diberikan.

Algoritma Naive Bayes merupakan metode data mining yang termasuk kedalam sepuluh klasifikasi data mining yang paling popular diantara algoritmaalgoritma lainnya (Saputra, Taufik, Ramdhani, Oktapian, \& Marsusanti, 2018)

Data mining sendiri memiliki arti menganalisis data dari perspektif yang berbeda dan meringkasnya menjadi informasi yang berguna (Medkhar et al., 2013)

Data mining memiliki beberapa tahapan yaitu data cleaning, data integration, data transformation, teknik data mining, patern evaluation, knowledge presentation (Peling, Arnawan, Arthawan, \& Janardana, 2017).

Tahapan data mining ada 6 dengan penjelasan sebagai beirkut (Meilani \& Susanti, 2015):

a. Data Cleaning

Proses menghilangkan data yang tidak konsisten atau data yang tidak relevan

b. Data Integration

Penggabungan atau mengkombinasikan sebuah data dari beberapa sumber.

c. Data Selection

Pemilihan data dari sekumpulan data operasional sebelum mendapatkan inforamsi knowledge discovery in database.

d. Data Transformation

Data diubah atau digabung ke dalam format yang sesuai untuk diproses dalam data mining.

e. Data Mining
Proses utama saat metode ditereapkan untuk menemukan pengetahuan atau informasi dari data.

f. Pattern Evaluation

Untuk mengidentifikasi pola-pola menarik kedalam knowledge based yang ditemukan.

g. Knowledge presentation

Pengetahuan mengenai metode yang digunakan untuk memperoleh pengetahuan yang diperoleh pengguna

\section{Metode Penelitian}

Metode Naïve Bayes merupakan metode yang memanfaatkan metode probabilitas dan statistik yang dikemukakan oleh ilmuwan Inggris Thomas Bayes. Naïve Bayes merupakan metode pengklasifikasian yang sangat sederhana dengan mengasumsikan klasifikasi atribut. Dengan metode Naive Bayes terlebih dahulu mencari Nilai Probabilitas dan likelihood maksimum dari setiap atribut untuk masing-masing kelas (Karthika \& Sairam, 2015).

\subsection{Probabilitas Prior}

Persamaan dari probabilitas prior:

$$
P(H)=\frac{N j}{N}
$$

Dimana:

$\mathrm{Nj} \quad$ : Jumlah data pada suatu class

$\mathrm{N}$ : Jumlah total data

\subsection{Probabilitas Posterior}

Persamaan dari teorema bayes (Saputra et al., 2018):

$$
P(H \mid X)=\frac{P(X \mid H) \cdot P(H)}{P(X)}
$$

Dimana:

$X$ : Data dengan class yang belum diketahui

H : Hipotesis data merupakan suatu class spesifik

$\mathrm{P}(\mathrm{H} \mid \mathrm{X})$ : Probabilitas Hipotesis $\mathrm{H}$ berdasarkan kondisi $\mathrm{X}$ (posterior probabilitas)

$\mathrm{P}(\mathrm{H}) \quad$ :Probabilitas hipotesis $\mathrm{H}$ (prior probabilitas)

$\mathrm{P}(\mathrm{X} \mid \mathrm{H})$ : probabilitas $\mathrm{X}$ berdasarkan kondisi pada hipotesis $\mathrm{H}$

$P(X) \quad$ : Probabilitas $X$

Penentuan class dilakukan dengan cara membandingkan nilai probabilitas suatu sampel berada di class yang satu dengan nilai probabilitas suatu sampel berada di class yang lain. 
Untuk menentukan class yang cocok dari suatu sampel dilakukan dengan cara membandingkan nilai posterior untuk masing-masing class, dan mengambil class dengan nilai posterior yang tertinggi.

\section{Hasil dan Pembahasan}

Data yang digunakan dalam penelitian ini diperoleh dari UCl Machine Learning Repository. Jumlah Data Dresses_attribute_sales sebanyak 500 data, dalam penentuan rekomendasi menggunakan atribut yang terdiri dari 12 atribut dan 1 atribut yang digunakan untuk class rekomendasi. Atribut yang digunakan yaitu style, price, rating, size, season, neckline, sleevelength, waiseline, matrial, fabrictype, decoration, pattern type dan recommendation. Dari data dresses_attribute_sales, ada 290 data gaun yang tidak rekomended untuk dibeli dan ada 210 data gaun yang rekomended untuk dibeli.

\subsection{Probabilitas Prior}

Nilai probabilitas prior dihitung berdasarkan data masa lalu. Total semua data 500 dengan class yang berbeda, 290 dengan class 0 yang artinya tidak rekomended, dan 210 dengan class 1 yang artinya rekomended. Nilai probabilitas prior digunakan untuk menghitung nilai probabilitas prior dari setiap atribut.

Tabel 1. Atribut

\begin{tabular}{|l|l|l|}
\hline No & Nama Atribut & Status Atribut \\
\hline 1 & Style & Diketahui \\
\hline 2 & Price & Diketahui \\
\hline 3 & Rating & Diketahui \\
\hline 4 & Size & Diketahui \\
\hline 5 & Season & Diketahui \\
\hline 6 & Neckline & Diketahui \\
\hline 7 & Sleevelength & Diketahui \\
\hline 8 & Waiseline & Diketahui \\
\hline 9 & Material & Diketahui \\
\hline 10 & Fabrictype & Diketahui \\
\hline 11 & Decoration & Diketahui \\
\hline 12 & Patterntype & Diketahui \\
\hline 13 & Recommendation & Dicari \\
\hline
\end{tabular}

Tabel 2. Nilai Atribut

\begin{tabular}{|l|l|}
\hline Nama Atribut & \multicolumn{1}{|c|}{ Nilai Atribut } \\
\hline Style & Bohemian, Brief, \\
& Casual, Cute, Fashion, \\
& $\begin{array}{l}\text { Flare, Novelty, OL, } \\
\text { Party, Sexy, Vintage, } \\
\\
\text { Work }\end{array}$ \\
\hline Price & Average, High, Low, \\
\hline
\end{tabular}

\begin{tabular}{|c|c|}
\hline & Medium, Very-High \\
\hline Rating & $0-5$ \\
\hline Size & Free, L, M, S, Small, XL \\
\hline Season & $\begin{array}{l}\text { Automn, Autumn, } \\
\text { Spring, Summer, Winter }\end{array}$ \\
\hline Neckline & $\begin{array}{l}\text { Backless, Boat-neck, } \\
\text { Bowneck, Halter, } \\
\text { Mandarin-collor, Null, o- } \\
\text { neck, Open, Peterpan- } \\
\text { collor, Ruffled, Scoop, } \\
\text { Slash-neck, Sqare- } \\
\text { collor, Sweetheart, } \\
\text { Turndowncollor, V-Neck }\end{array}$ \\
\hline Sleevelength & $\begin{array}{l}\text { Butterfly, Caps-leeves, } \\
\text { Full, Half, Halfsleeves, } \\
\text { Null, Petal, Short, } \\
\text { Sleeveless, } \\
\text { Threequarter, } \\
\text { Thressqatar, } \\
\text { Turndowncollor, } \\
\text { Urndowncollor }\end{array}$ \\
\hline Waiseline & $\begin{array}{l}\text { Dropped, } \quad \text { Empire, } \\
\text { Natural, Null, Princess }\end{array}$ \\
\hline Material & \begin{tabular}{lrr} 
Acrylic, & \multicolumn{2}{r}{ Cashmere, } \\
Chiffonfabric, & Cotton, \\
Knitting, lace, linen, \\
lycra, \\
Milksilk, Mix, Modal, \\
Model, Null, Nylon, \\
Other, Polyster, Rayon, \\
Shiffon, Silk, Sill, \\
Spandex, Viscos, Wool.
\end{tabular} \\
\hline Fabrictype & $\begin{array}{l}\text { Batik, Broadcloth, } \\
\text { chiffon, } \quad \text { Corduroy, } \\
\text { Dobby, Flannel, Jersey, } \\
\text { Knitted, Knitting, lace, } \\
\text { null, Organza, Other, } \\
\text { Poplin, Satin, Shiffon, } \\
\text { Terry, Tulle, Woolen }\end{array}$ \\
\hline Decoration & $\begin{array}{l}\text { Applique, Beading, Bow, } \\
\text { Button }\end{array}$ \\
\hline Patterntype & $\begin{array}{l}\text { Animal, dot, geometric, } \\
\text { null, patchwork, plaid, } \\
\text { print, solid, striped }\end{array}$ \\
\hline Recommendation & Ya, Tidak \\
\hline
\end{tabular}

Diketahui data tes untuk menghitung nilai probabilitas di setiap atribut. Berikut adalah data tes yang ada dapat dilihat pada tabel 3.3

Tabel 3. Data Tes

\begin{tabular}{|l|l|}
\hline Dress_ld & 919930954 \\
\hline Style & Casual \\
\hline Price & Low \\
\hline Rating & 4,4 \\
\hline Size & Free \\
\hline
\end{tabular}




\begin{tabular}{|l|l|}
\hline Season & Summer \\
\hline Neckline & V-Neck \\
\hline SleeveLength & Short \\
\hline Waiseline & Empire \\
\hline Material & Cotton \\
\hline FabricType & Chiffon \\
\hline Decoration & Lace \\
\hline PatternType & Solid \\
\hline Recommendation & $?$ \\
\hline
\end{tabular}

Tabel 4. Nilai Probabilitas Prior Atribut

\begin{tabular}{|c|c|c|c|c|}
\hline \multirow{2}{*}{$\begin{array}{l}\text { Atribut } \\
\text { Style }\end{array}$} & \multicolumn{2}{|c|}{ Nilai Atribut } & \multirow{2}{*}{$\begin{array}{c}\begin{array}{c}\text { Jumlah } \\
\text { Data }\end{array} \\
210\end{array}$} & \multirow{2}{*}{$\begin{array}{c}\begin{array}{c}\mathbf{P} \\
(\mathbf{X} \mid \mathbf{C})\end{array} \\
0,42\end{array}$} \\
\hline & $\begin{array}{l}\text { Casual } \\
\text { (Ya) }\end{array}$ & 89 & & \\
\hline & $\begin{array}{l}\text { Casual } \\
\text { (Tidak) }\end{array}$ & 143 & 290 & 0,49 \\
\hline \multirow[t]{2}{*}{ Price } & $\begin{array}{l}\text { Low } \\
(\mathrm{Ya})\end{array}$ & 72 & 210 & 0,34 \\
\hline & $\begin{array}{l}\text { Low } \\
\text { (Tidak) }\end{array}$ & 102 & 290 & 0,35 \\
\hline \multirow[t]{2}{*}{ Rating } & $\begin{array}{l}4,4 \\
(\mathrm{Ya})\end{array}$ & 6 & 210 & 0,03 \\
\hline & $\begin{array}{l}4,4 \\
\text { (Tidak) }\end{array}$ & 21 & 290 & 0,07 \\
\hline \multirow[t]{2}{*}{ Size } & $\begin{array}{l}\text { Free } \\
(\mathrm{Ya})\end{array}$ & 77 & 210 & 0,37 \\
\hline & $\begin{array}{l}\text { Free } \\
\text { (Tidak) }\end{array}$ & 96 & 290 & 0,33 \\
\hline \multirow[t]{2}{*}{ Season } & $\begin{array}{l}\text { Summ } \\
\text { er (Ya) }\end{array}$ & 54 & 210 & 0,26 \\
\hline & $\begin{array}{l}\text { Summ } \\
\text { er } \\
\text { (Tidak) }\end{array}$ & 106 & 290 & 0,37 \\
\hline \multirow[t]{2}{*}{$\begin{array}{l}\text { Necklin } \\
\mathrm{e}\end{array}$} & $\begin{array}{l}\text { V- } \\
\text { Neck } \\
\text { (Ya) }\end{array}$ & 60 & 210 & 0,29 \\
\hline & $\begin{array}{l}\text { V- } \\
\text { Neck } \\
\text { (Tidak) }\end{array}$ & 64 & 290 & 0,22 \\
\hline \multirow[t]{2}{*}{$\begin{array}{l}\text { SleeveL } \\
\text { ength }\end{array}$} & $\begin{array}{l}\text { Short } \\
\text { (Ya) }\end{array}$ & 27 & 210 & 0,13 \\
\hline & $\begin{array}{l}\text { Short } \\
\text { (Tidak) }\end{array}$ & 69 & 290 & 0,24 \\
\hline \multirow[t]{2}{*}{$\begin{array}{l}\text { Waiseli } \\
\text { ne }\end{array}$} & $\begin{array}{l}\text { Empire } \\
(\mathrm{Ya})\end{array}$ & 47 & 210 & 0,22 \\
\hline & $\begin{array}{l}\text { Empire } \\
\text { (Tidak) }\end{array}$ & 57 & 290 & 0,20 \\
\hline \multirow[t]{2}{*}{ Material } & $\begin{array}{l}\text { Cotton } \\
(\mathrm{Ya})\end{array}$ & 64 & 210 & 0,30 \\
\hline & $\begin{array}{l}\text { Cotton } \\
\text { (Tidak) }\end{array}$ & 88 & 290 & 0,30 \\
\hline \multirow[t]{2}{*}{$\begin{array}{l}\text { Fabric } \\
\text { Type }\end{array}$} & $\begin{array}{l}\text { Chiffon } \\
\text { (Ya) }\end{array}$ & 57 & 210 & 0,27 \\
\hline & $\begin{array}{l}\text { Chiffon } \\
\text { (Tidak) }\end{array}$ & 78 & 290 & 0,27 \\
\hline
\end{tabular}

\begin{tabular}{|l|l|c|c|c|}
\hline \multirow{2}{*}{$\begin{array}{l}\text { Decorat } \\
\text { ion }\end{array}$} & $\begin{array}{l}\text { Lace } \\
\text { (Ya) }\end{array}$ & 32 & 210 & 0,15 \\
\cline { 2 - 5 } & $\begin{array}{l}\text { Lace } \\
\text { (Tidak) }\end{array}$ & 38 & 290 & 0,13 \\
\hline $\begin{array}{l}\text { Pattern } \\
\text { Type }\end{array}$ & $\begin{array}{l}\text { Solid } \\
\text { (Ya) }\end{array}$ & 79 & 210 & 0,38 \\
\cline { 2 - 5 } & $\begin{array}{l}\text { Solid } \\
\text { (Tidak) }\end{array}$ & 124 & 290 & 0,43 \\
\hline
\end{tabular}

\subsection{Probabilitas Posterior}

Perhitungan pada probabilitas posterior digunakan untuk menentukan class terhadap data baru yang akan diklasifikasikan. Berikut adalah perhitungan probabilitas posterior dari data tes pada tabel 3.3:

$\mathrm{P}(\mathrm{X} \mid$ Recommendation $)=$ $\mathrm{P}($ Casual|Recommendation $)$ * $\mathrm{P}($ Low $\mid$ Recommendation $)$ * $\mathrm{P}(4,4 \mid$ Recommendation $)$ * $\mathrm{P}($ Free $\mid$ Recommendation $)$ * $\mathrm{P}$ (Summer|Recommendation) * $\mathrm{P}(\mathrm{V}-\mathrm{Neck} \mid$ Recommendation $)$ * $\mathrm{P}$ (Short|Recommendation) * $\mathrm{P}($ Empire $\mid$ Recommendation $)$ * $\mathrm{P}($ Cotton|Recommendation $)$ * $\mathrm{P}($ Chiffon|Recommendation $)$ * $\mathrm{P}$ (Lace|Recommendation) * $\mathrm{P}$ (Solid|Recommendation) * $=0,42^{*} 0,34^{*} 0,03^{*} 0,37^{*} 0,26^{*} 0,29^{*} 0,13^{*}$ $0,22^{*} 0,30^{*} 0,27^{\star} 0,15^{\star} 0,38^{\star} 210$ $=0,00000320$

$\mathrm{P}(\mathrm{X} \mid$ NonRecommendation $)=$ $\mathrm{P}$ (Casual|NonRecommendation) * $\mathrm{P}($ Low $\mid$ NonRecommendation $)$ * $\mathrm{P}(4,4 \mid$ NonRecommendation $)$ * $\mathrm{P}$ (Free|NonRecommendation) * $\mathrm{P}$ (Summer|NonRecommendation) * $\mathrm{P}(\mathrm{V}-$ Neck|NonRecommendation) * $\mathrm{P}$ (Short|NonRecommendation) * $\mathrm{P}($ Empire|NonRecommendation $)$ * $\mathrm{P}$ (Cotton|NonRecommendation) * $\mathrm{P}$ (Chiffon|NonRecommendation) * $\mathrm{P}$ (Lace|NonRecommendation) * $\mathrm{P}$ (Solid|NonRecommendation) * $=0,49^{*} 0,35^{*} 0,07^{*} 0,33^{*} 0,37^{*} 0,22^{*} 0,24^{*}$ $0,20^{*} 0,30^{*} 0,27^{*} 0,13^{*} 0,43^{*} 290$ $=0,00002080$

\section{Kesimpulan}

Dapat ditarik kesimpulan dari penelitian ini sebagai berikut:

a. Melihat hasil dari probabilitas posterior bahwa $\mathrm{P}(\mathrm{X} \mid$ Recommendation) lebih kecil di bandingkan hasil $\mathrm{P}(\mathrm{X} \mid$ NonRecommendation $)$, maka dapat 
diketahui bahwa data tes ini termasuk data NonRecommendation.

b. Naïve Bayes merupakan metode yang dapat membantu dalam menyelesaikan masalah klasifikasi seperti rekomendasi pakaian wanita.

c. Naïve Bayes sangat baik digunakan untuk mendukung penunjang keputusan.

d. Metode Naïve Bayes merupakan metode klasifikasi dengan teorema bayes yang dikenal dengan ilmu probabilitas.

\section{Referensi}

Karthika, S., \& Sairam, N. (2015). A Naïve Bayesian Classifier for Educational Qualification. Indian Journal of Science and Technology, 8(16), 1-5. http://doi.org/10.17485/ijst/2015/v8i16/ 62055

Mariana, P., Setiawan, H., \& Irawan, P. L. T. (2015). Implementasi Augmented Reality Untuk Visualisasi Pakaian Wanita. SMATIKA Jurnal2, 5(2), 5157.

Medkhar, D. S., Bote, M. P., \& Deshmukh, S. D. (2013). Heart Disease Prediction System Using Naive Bayes. International Journal Of Enhanced Research In Science Technology \& Engineering, 2(3), 1-5. http://doi.org/10.1093/infdis/139.2.232
Meilani, B. D., \& Susanti, N. (2015). Aplikasi Data Mining Untuk Menghasilkan Pola Kelulusan Siswa Ddengan Metode Naive Bayes. Jurnal IImiah NERO, 1(3), 182-189.

Peling, I. B. A., Arnawan, I. N., Arthawan, I. P. A., \& Janardana, I. (2017). Implementation of Data Mining To Predict Period of Students Study Using Naive Bayes Algorithm. International Journal of Engineering and Emerging Technology, 2(1), 5357.

Saleh, A. (2015). Implementasi Metode Klasifikasi Naive Bayes Dalam Memprediksi Besarnya Penggunaan Listrik Rumah Tangga. CITEC Journal, 2(3), 207-217. http://doi.org/doi.org/10.24076/citec.20 $15 \mathrm{v} 2 \mathrm{i} 3.49$

Saputra, R. A., Taufik, A. R., Ramdhani, L. S., Oktapian, R., \& Marsusanti, E. (2018). Sistem Pendukung Keputusan Dalam Menentukan Metode Kontrasepsi Menggunakan Algoritma Naive Bayes. SNIT 2018, 106-111.

Suryadi, A., \& Harahap, E. (2018). Sistem Rekomendasi Penerimaan Mahasiswa Baru Menggunakan Naive Bayes Classifier Di Institut Pendidikan Indonesia. JOUTICA, 3(2), 171-182. 